\title{
The spatial distribution of forest carbon sinks and sources in China
}

\author{
LIU ShuangNa ${ }^{1,2}$, ZHOU Tao ${ }^{1,2 *}$, WEI LinYan ${ }^{1,2} \&$ SHU Yang ${ }^{2,3}$ \\ ${ }^{1}$ State Key Laboratory of Earth Surface Processes and Resource Ecology, Beijing Normal University, Beijing 100875, China; \\ ${ }^{2}$ Academy of Disaster Reduction and Emergency Management, Ministry of Civil Affairs and Ministry of Education, Beijing 100875, China; \\ ${ }^{3}$ Key Laboratory of Environmental Change and Natural Disaster, Beijing 100875, China
}

Received October 18, 2011; accepted January 6, 2012; published online March 8, 2012

\begin{abstract}
Forest ecosystems play an important role in the global carbon cycle. The implementation of the United Nations Framework Convention on Climate Change (UNFCCC) and the Kyoto Protocol has made the study of forest ecosystem carbon cycling a hot topic of scientific research globally. This paper utilized Chinese national forest inventory data sets (for the periods 1984-1988 and 1999-2003), the vegetation map of China (1:1000000), and the spatially explicit net primary productivity (NPP) data sets derived with the remote sensing-based light use efficiency model (CASA model). We quantitatively estimated the spatial distribution of carbon sinks and sources of forest vegetation (with a resolution of $1 \mathrm{~km}$ ) using the spatial downscaling technique. During the period 1984 to 2003 the forest vegetation in China represented a carbon sink. The total storage of carbon increased by $0.77 \mathrm{PgC}$, with a mean of $51.0 \mathrm{TgC} \mathrm{a}^{-1}$. The total carbon sink was $0.88 \mathrm{PgC}$ and carbon source was $0.11 \mathrm{PgC}$ during the study period. The carbon sink and carbon source of forest vegetation in China showed a clear spatial distribution pattern. Carbon sinks were mainly located in subtropical and temperate regions, with the highest values in Hainan Province, Hengduan mountain ranges, Changbai mountain ranges in Jilin, and south and northwest of the Da Hinggan Mountains; carbon sources were mainly distributed from the northeast to southwestern areas in China, with the highest values mainly concentrated in southern Yunnan Province, central Sichuan Basin, and northern Da Hinggan Mountains. Increase in NPP was strongly correlated with carbon sink strength. The regression model showed that more than $80 \%$ of the variation in the modeled carbon sinks in Northeast, Northern, Northwest and Southern China were explained by the variation in NPP increase. There was a strong relationship between carbon sink strength and forest stand age.
\end{abstract}

forest, carbon sinks, carbon sources, downscaling, spatial distribution, China

Citation: $\quad$ Liu S N, Zhou T, Wei L Y, et al. The spatial distribution of forest carbon sinks and sources in China. Chin Sci Bull, 2012, 57: 1699-1707, doi: $10.1007 / \mathrm{s} 11434-012-4998-1$

A small change in the global and regional carbon cycle and carbon budget will lead to a significant fluctuation in the atmospheric concentration of $\mathrm{CO}_{2}$ and the stability of the global climate [1]. The carbon cycle and the Kyoto Protocol make the global and regional carbon cycle hot spots of global change research. Although the academic community affirms the carbon sink function of the terrestrial ecosystem, there is still much uncertainty with carbon sinks quantity and spatial distribution [2]. As the biggest carbon stock in the terrestrial ecosystem [3], forest ecosystems are of great importance. Therefore determining the spatial distribution

*Corresponding author (email: tzhou@bnu.edu.cn) of the carbon source and carbon sink of the Chinese forest ecosystem will be extremely helpful for our research into the carbon cycle of the terrestrial ecosystem and to address global warming.

Currently, the traditional methods of obtaining the terrestrial ecosystem carbon storage are mainly as follows: field survey data of plant biomass and soil carbon storage; satellite remote sensing; inversion of atmospheric $\mathrm{CO}_{2}$ concentration; ecosystem model simulations [4]. Because of the relative merits of these methods, evaluations of the terrestrial carbon source from different yardsticks are different [5-9]. For instance, the evaluation of the Chinese forest carbon storage by Zhao et al. [10] from 1989 to 1993 dou- 
bled estimate made by Zhou et al. [11]. Piao et al. [12] found that different estimates of the carbon source of the same region (Northeast China) were obtained with different methods, such as a process-based model, atmospheric and remote sensing inversion model.

To reduce the uncertainty of the evaluation as well as to demonstrate the spatial distribution of carbon sources and carbon sinks, combination of satellite remote sensing data with reference data from forest resource surveys to exploit the advantages of the accuracy of spatial orientation and remote sensing data and field survey data is very important. In recent years, the method of combining forest inventory investigation with remote sensing data and using downscaling to estimate the ecosystem features has been widely applied in the USA, Finland and other European countries [13-17]. By utilizing statistical data from the 1984-1988 and 1999-2003 national forest resource surveys, the 1: 1000000 forest vegetation map, and the spatial distribution of NPP derived with the CASA model, we quantitatively estimated the spatial distribution of the Chinese forest carbon source and carbon sink from 1984 to 2003 (1 km resolution) with the help of downscaling method.

\section{Statistics and methods}

\subsection{Statistics}

The specific forest inventory statistics were obtained from the Statistics of National Forest Vegetation (for the periods 1984-1988 and 1999-2003), which was published by the Forest Resources Management Department of State Forestry Administration. The forest type statistics were obtained from the National Vegetation Map of the People's Republic of China $(1: 1000000)$, which demonstrate the Chinese forest vegetation situation in the 1980s and 1990s.

In this research we used GIMMS NDVI data (http://www. glcf.umd.edu/data/gimms), which are derived from imagery captured by the Advanced Very High Resolution Radiometer (AVHRR) onboard the NOAA satellites. The data set comprised the maximized normalized difference vegetation index (NDVI) compounded every 15 days. GIMMS NDVI products had conducted a variety of correction, eliminating the impact of the aging of the sensor, the satellite orbit offsets, solar zenith angle changes [18-20].

NPP data from light-use efficiency models (CASA model) based on remote sensing data. CASA model can simulate NPP spatial distribution and changes in the regional scale, which is widely used in NPP monitoring by a variety of spatial scales [21-23]. The accuracy of its estimations has been demonstrated by ground truth measurement [24,25].

\subsection{Methods}

The present assessment was based on the concept of downscaling of Kindermann et al. [16]. Amendments were added to make it more applicable to Chinese forest ecosystems. The methodology used is shown in Figure 1 and the procedures are as follows:

(i) Generation of NPP data. By calculation of the average monthly NDVI of the 1984-1988 and 1999-2003 surveys and Kriging interpolation of the meteorological data from over 600 measurement sites, we achieved coherence of all of the data in terms of projection and spatial resolution. Then, we input the average monthly data for NDVI, temperature, precipitation and radiation into the CASA model to estimate the annual NPP during the periods 1984-1988 and 1999-2003. Finally, we derived the average annual data for the two periods. This multi-year averaged climatic data were applied to reduce the uncertainty caused by the annual fluctuation of climatic factors [26].

(ii) Computation of statistics for carbon storage in the forest vegetation. Taking the Technical Regulations on the Survey of National Forest Resource as a reference, we classified the 700 dominant tree species sampled in the two periods into three forest types (coniferous forest, broadleaf forest and mixed conifer-broadleaf forest). Next we used the biomass expansion factor function [27,28] to estimate the average value of the carbon storage of the three forest types in each province during the 1984-1988 and 1999-2003 periods. Finally, we adjusted the average value of the carbon storage of the three forest types in each province from 1984 to 1988 by using the criteria of $20 \%$ and $30 \%$ canopy density [29].

(iii) Computation of a distribution map of the average carbon storage of the forest types. First, the forest type map was based on the attribute data of the National Vegetation Map of the People's Republic of China $(1: 1000000)$ to determine the distribution of the three forest types (coniferous forest, broadleaf forest and mixed forest) in China. Second, we matched the processed distribution map with the average value of the carbon storage of the three forest types during the 1984-1988 and 1999-2003 periods to obtain a spatial distribution map of carbon storage for the forest vegetation.

(iv) Computation of a distribution map of carbon sources and carbon sinks. On the basis of the two-period spatial distribution map of carbon storage for the forest vegetation, we used the method of spatial downscaling methed to calculate a two-period carbon density distribution map for the forest vegetation at a resolution of $1 \mathrm{~km}$, and to obtain a spatial distribution map of carbon sources and carbon sinks for the Chinese forest vegetation.

Submodel of the CASA-NPP. On the basis of the CASA model, NPP can be calculated from data for NDVI, photosynthetically active radiation (PAR), the maximized potential light use efficiency $\left(\varepsilon^{*}\right)$, temperature function $g(T)$ and soil moisture function $h(w)$ [21,30]:

$$
\mathrm{NPP}=\mathrm{PAR} \times f(\mathrm{NDVI}) \times \varepsilon^{*} \times g(T) \times h(w) .
$$

The value for PAR in this formula can be obtained from 


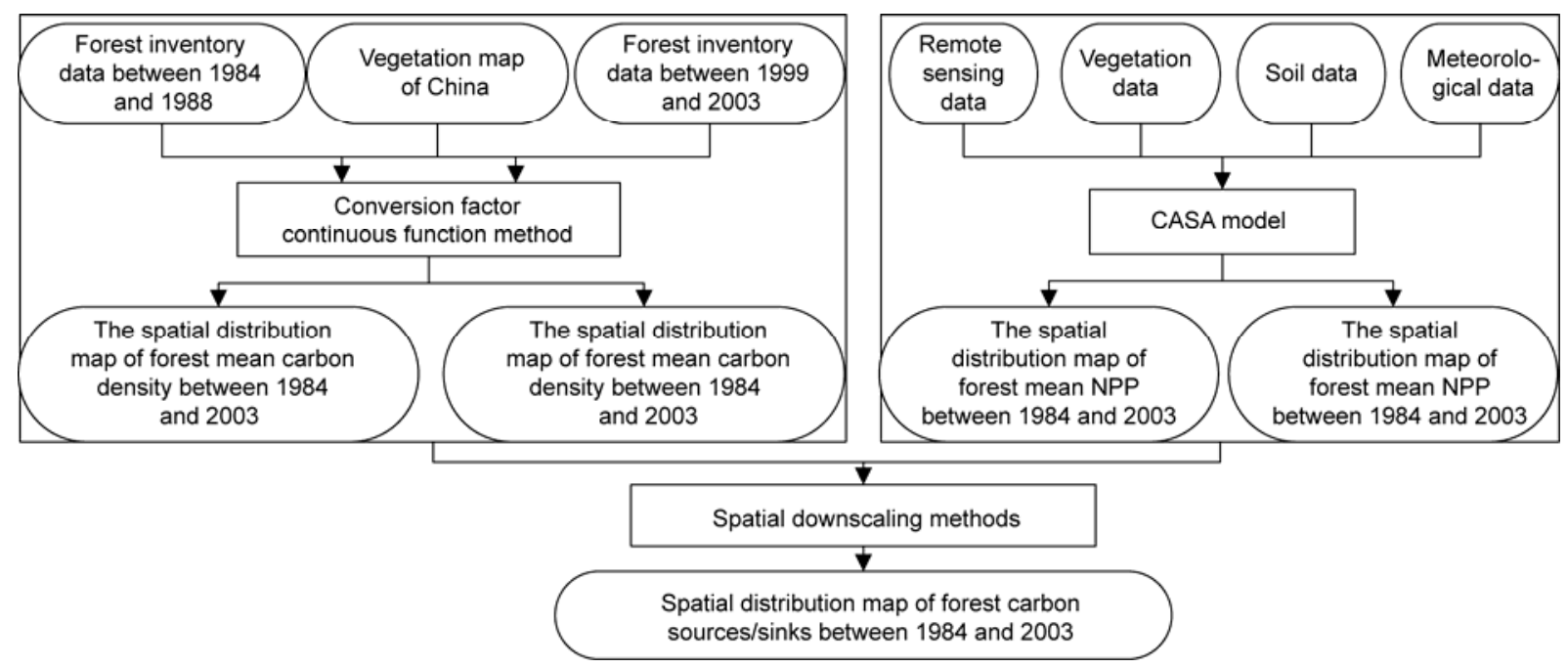

Figure 1 Flow diagram summarizing the methodology for estimation of the spatial distribution of Chinese carbon sources and sinks.

estimation of downward shortwave radiation ( $\mathrm{PAR}=0.5 \mathrm{R})$. Data for downward shortwave radiation used in the present study were the average monthly observed radiation at 120 sites obtained from the Meteorological Administration; of the total PAR that arrives at Earth, only part of it will be absorbed, and the proportion absorbed depends on the condition of the ground and is a function of the standardized NDVI, namely $f(\mathrm{NDVI})$, which represents the percentage of the total PAR absorbed by the vegetation. Therefore, PAR $\times f($ NDVI) in equation (1) equals the PAR absorbed by the vegetation (APAR); apart from the light energy in the model of the light use efficiency, NPP is also determined by the conversion rate of the light energy, which is converted into organic compounds by the vegetation $(\varepsilon)$, thus NPP equals the product of APAR and the light use efficiency. The light use efficiency of vegetation $(\varepsilon)$ is influenced by the temperature and moisture of the surroundings, so we used the function of the maximized potential light use efficiency $\left(\varepsilon^{*}\right)$, temperature $(T)$ and moisture $(w), \varepsilon=\varepsilon^{*} \times g(T) \times$ $h(w)$. The value of $\varepsilon^{*}$ is determined by the forest type, therefore it is constant for a certain forest type.

Downscaling method. The downscaling method used in this research was based on Kindermann et al.'s method [16]. Taking the average value of the carbon storage of the three forest types derived from the forest resource inventory as a foundation, the forest distribution map and NPP spatial distribution data as link, we derived an transfer function related to the quantity of spatial grids and the corresponding NPP together with the average value of carbon density of the same forest type. Thus, eq. (2) was used to calculate the carbon storage of each spatial grid.

$$
C_{i}=\frac{\overline{C_{p t}} \times N_{i} \times n}{\sum_{i \in p \cap t} N_{i}}(p=1,2,3 \cdots, 30)(t=1,2,3)(i=1,2,3 \cdots, n),
$$

where $p=$ the province, $t=$ the forest type (coniferous forest, broadleaf forest, mixed conifer-broadleaf forest), $i=\mathrm{a}$ specific grid, $\overline{C_{p t}}=$ the average carbon storage of a specific forest type in a specific province $\left(\mathrm{MgC} \mathrm{ha}^{-1}\right) ; N_{i}=$ the NPP of the forest of a grid $\left(\mathrm{gC} \mathrm{m}^{-2} \mathrm{a}^{-1}\right) ; C_{i}=$ the forest carbon storage of a grid; and $n=$ the number of the grids of a specific forest in a province.

\section{Results and discussion}

\subsection{Spatial distribution of carbon sinks}

Taking the reference from the 1984-1988 and 1999-2003 forest resource surveys (the time span is 15 years), the $1: 1000000$ forest vegetation map, and estimation of the spatial distribution of NPP derived with the CASA model, we quantitatively estimated the spatial distribution of Chinese forest carbon sources and carbon sinks from 1984 to 2003 with a resolution of $1 \mathrm{~km}$ using the spatial downscaling technique (Figure 2). The map projection used is the Albers authalic conical projection. The standard latitude line is $25^{\circ} \mathrm{N}$ and $47^{\circ} \mathrm{N}$, and the central longitude line is $110^{\circ} \mathrm{E}$. From 1984 to 2003, the Chinese forest ecosystem mainly represented a carbon sink, which agrees well with the specific growth trend for NPP [31]. The total area of carbon sinks was $107.29 \times 10^{6}$ ha $(76.6 \%$ of the total forest vegetation), the quantity of carbon fixation was $0.88 \mathrm{PgC}$, and the average annual carbon fixation was about $58.67 \mathrm{TgC} \mathrm{a}^{-1}$. From a spatial distribution perspective, some patterns in the distribution of carbon sinks in the Chinese forest vegetation were notable. The area of carbon sink forests declined from Southeast to Northwest China, and zones of high carbonsink values were concentrated in Hainan Province, Hengduan mountain ranges and the Changbai mountain ranges in Jilin Province. During the study period, the area of carbon 


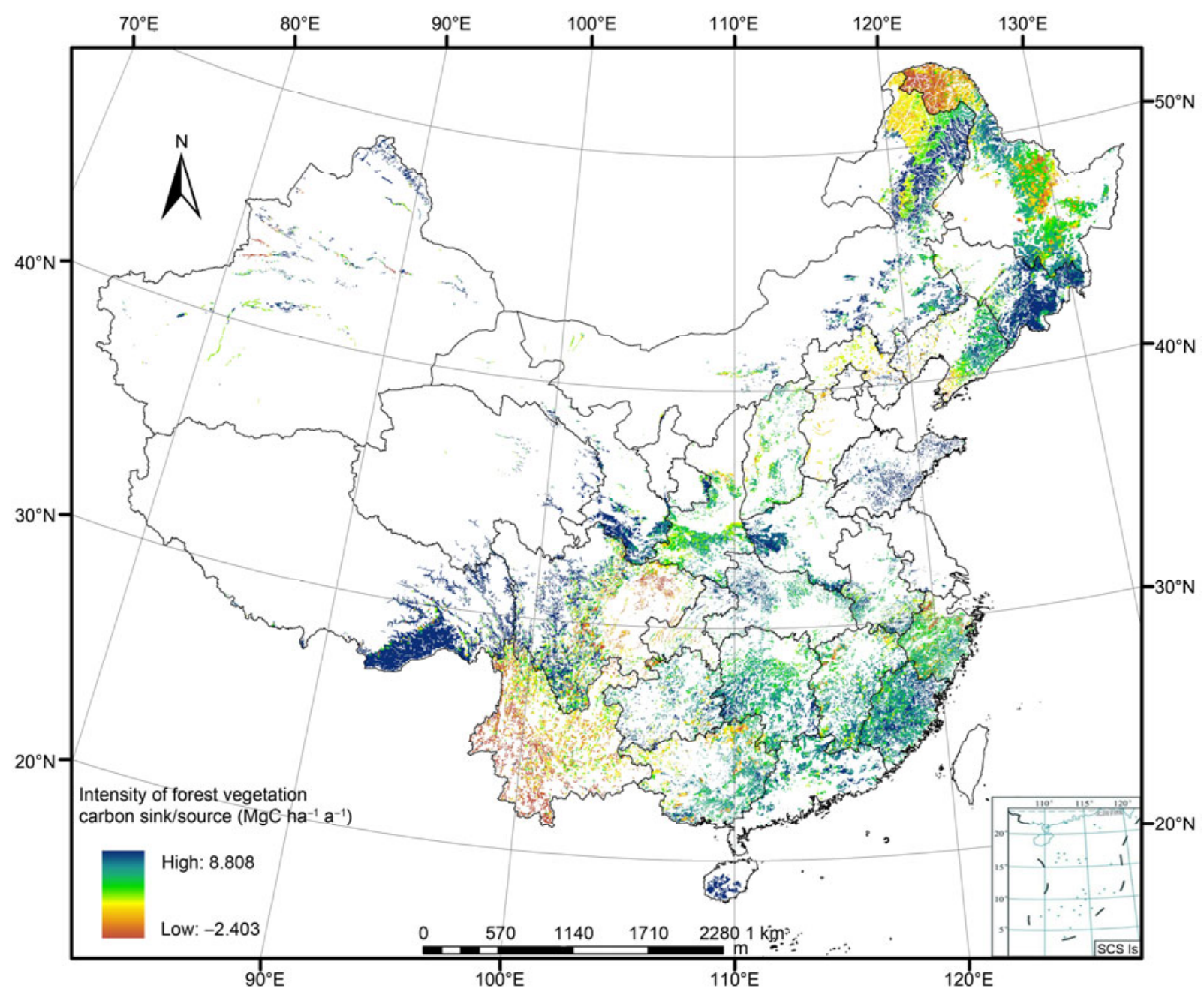

Figure 2 Spatial distribution of China's forest vegetation carbon sinks and sources between 1984 and 2003 (not including Taiwan). Positive values represent a carbon sink, negative values represent a carbon source.

sources was $32.81 \times 10^{6}$ ha $(23.4 \%$ of the total forest vegetation), the quantity of carbon release was $0.11 \mathrm{PgC}$ and the average annual carbon release was $7.33 \mathrm{TgC} \mathrm{a}^{-1}$. From a spatial distribution perspective, the carbon source forests were distributed from Northeast to Southwest China, and zones of high carbon-source values were concentrated in southern Yunnan Province and northern Da Hinggan Mountains.

From 1984 to 1988, the forest vegetation represented a carbon sink in all provinces except Yunnan. The ranking of administrative regions that showed a high quantity of carbon fixation (in descending order) was Xizang, Inner Mongolia, Sichuan, Jilin and Xinjiang. The ranking of administrative regions that showed a low quantity of carbon fixation (in ascending order) was Tianjin, Beijing, Ningxia, Jiangsu and Hebei. The ranking of administrative regions on the basis of carbon net budget was Xizang, Inner Mongolia, Jilin and Sichuan (Table 1). During the period from 1984 to 2003, the quantities of carbon fixation by broadleaf forest was 445.70 $\times 10^{6} \mathrm{MgC}$, coniferous forest $417.40 \times 10^{6} \mathrm{MgC}$ and mixed forest $16.65 \times 10^{6} \mathrm{MgC}$ (Table 2). The average annual densities of carbon fixation by each forest type were $60.83,51.56$, and $24.83 \mathrm{gC} \mathrm{m}^{-2} \mathrm{a}^{-1}$, respectively. The ranking of the forests on the basis of their carbon density was half-mature forest, large sapling forest, near-mature forest, mature forest and over-mature forest. The density of carbon sinks declined with the increase in forest age.

To conclude from all of the forest grids, Chinese forest ecosystems mainly represented carbon sinks, the net amount of carbon fixation was $0.77 \mathrm{PgC}$, and the average annual amount of carbon fixation was $51.0 \mathrm{TgC} \mathrm{a} \mathrm{a}^{-1}$. This result generally agrees with the findings of previous studies based on a model or statistical outcome (Table 3). Differences in the methodology and data used mean the estimations of carbon sinks in the Chinese forest vegetation differ considerably. The estimated annual amount of carbon fixation varies between 19 and $115 \mathrm{TgC} \mathrm{a}^{-1}$, and that of a unit area varies between 15 and $73.9 \mathrm{gC} \mathrm{m}^{-2} \mathrm{a}^{-1}$. Compared with other surveys, the carbon sinks estimated in this research are slightly lower, because this research has made a correction to the species in the period from 1984 to 1988. Before 1994, 
Table 1 Comparison of forest carbon sink/carbon source's area, total, intensity in administrative regions

\begin{tabular}{|c|c|c|c|c|c|c|c|}
\hline \multirow{2}{*}{$\begin{array}{l}\text { Administrative } \\
\text { regions }\end{array}$} & \multicolumn{3}{|c|}{ Carbon sink } & \multicolumn{3}{|c|}{ Carbon source } & \multirow{2}{*}{$\begin{array}{l}\text { Carbon buge } \\
\qquad(\mathrm{TgC})\end{array}$} \\
\hline & $\begin{array}{c}\text { Carbon sink } \\
\text { area }\left(\times 10^{6} \mathrm{ha}\right)\end{array}$ & $\begin{array}{c}\text { Carbon uptakes } \\
(\mathrm{Tg})\end{array}$ & $\begin{array}{c}\text { Strength of carbon } \\
\text { uptake }\left(\mathrm{MgC} \mathrm{ha}^{-1} \mathrm{a}^{-1}\right)\end{array}$ & $\begin{array}{l}\text { Carbon source } \\
\text { area }\left(\times 10^{6} \text { ha }\right)\end{array}$ & $\begin{array}{c}\text { Carbon emissions } \\
(\mathrm{Tg})\end{array}$ & $\begin{array}{c}\text { Strength of carbon } \\
\text { emissions }\left(\mathrm{MgC} \mathrm{ha}^{-1} \mathrm{a}^{-1}\right)\end{array}$ & \\
\hline Xizang & 8.96 & 367.18 & 2.73 & 0.31 & 0.95 & 0.21 & 366.23 \\
\hline Xinjiang & 2.00 & 36.14 & 1.20 & 0.34 & 2.67 & 0.52 & 33.47 \\
\hline Qinghai & 0.74 & 11.78 & 1.07 & 0.01 & 0.01 & 0.09 & 11.77 \\
\hline Yunnan & 1.64 & 4.00 & 0.16 & 8.36 & 48.73 & 0.39 & -44.73 \\
\hline Guangxi & 4.94 & 17.81 & 0.24 & 1.73 & 4.43 & 0.17 & 13.38 \\
\hline Gansu & 3.43 & 23.68 & 0.46 & 0.08 & 0.10 & 0.08 & 23.58 \\
\hline Sichuan & 8.04 & 55.24 & 0.46 & 4.19 & 14.50 & 0.23 & 40.74 \\
\hline Guangdong & 3.40 & 14.58 & 0.29 & 0.07 & 0.07 & 0.06 & 14.51 \\
\hline Shaanxi & 4.07 & 10.70 & 0.18 & 0.80 & 0.82 & 0.07 & 9.89 \\
\hline Ningxia & 0.07 & 0.91 & 0.84 & 0.00 & 0.00 & 0.18 & 0.90 \\
\hline Fujian & 7.51 & 33.62 & 0.30 & 0.16 & 0.21 & 0.09 & 33.41 \\
\hline Shanxi & 1.61 & 4.16 & 0.17 & 0.33 & 0.40 & 0.08 & 3.76 \\
\hline Hubei & 2.38 & 10.10 & 0.28 & 0.01 & 0.00 & 0.03 & 10.10 \\
\hline Henan & 2.56 & 13.26 & 0.35 & 0.02 & 0.01 & 0.04 & 13.25 \\
\hline Chongqing & 0.62 & 3.32 & 0.35 & 0.25 & 0.66 & 0.18 & 2.66 \\
\hline Jiangsu & 0.20 & 2.23 & 0.76 & 0.00 & 0.00 & 0.21 & 2.23 \\
\hline Shandong & 1.79 & 15.44 & 0.58 & 0.00 & 0.00 & 0.02 & 15.44 \\
\hline Anhui & 1.94 & 7.67 & 0.26 & 0.18 & 0.14 & 0.05 & 7.53 \\
\hline Guizhou & 2.77 & 12.02 & 0.29 & 0.58 & 1.67 & 0.19 & 10.35 \\
\hline Hunan & 7.17 & 27.08 & 0.25 & 0.16 & 0.23 & 0.10 & 26.86 \\
\hline Jiangxi & 4.65 & 17.00 & 0.24 & 0.84 & 1.84 & 0.15 & 15.15 \\
\hline Zhejiang & 3.82 & 10.68 & 0.19 & 1.01 & 3.54 & 0.23 & 7.14 \\
\hline Heilongjiang & 10.73 & 32.89 & 0.20 & 7.53 & 25.06 & 0.22 & 7.82 \\
\hline Jilin & 6.66 & 45.16 & 0.45 & 0.27 & 0.44 & 0.11 & 44.72 \\
\hline Inner Mongolia & 11.00 & 63.73 & 0.39 & 3.83 & 5.15 & 0.09 & 58.59 \\
\hline Hebei & 0.39 & 2.51 & 0.43 & 1.04 & 1.58 & 0.10 & 0.93 \\
\hline Liaoning & 3.45 & 15.86 & 0.31 & 0.71 & 1.29 & 0.12 & 14.57 \\
\hline Beijing & 0.06 & 0.63 & 0.75 & 0.00 & 0.00 & 0.10 & 0.62 \\
\hline Tianjin & 0.01 & 0.06 & 0.74 & 0.00 & 0.00 & 0.21 & 0.06 \\
\hline Hainan & 0.68 & 20.31 & 1.98 & 0.00 & 0.00 & 0 & 20.31 \\
\hline
\end{tabular}

Table 2 Comparison of carbon sink/carbon source's area, total, intensity in three forest types

\begin{tabular}{|c|c|c|c|c|c|}
\hline Forest type & $\begin{array}{c}\text { Carbon sinks } \\
(\mathrm{TgC})\end{array}$ & $\begin{array}{c}\text { Carbon sink area } \\
\left(\times 10^{6} \mathrm{ha}\right)\end{array}$ & $\begin{array}{c}\text { Carbon sources } \\
(\mathrm{TgC})\end{array}$ & $\begin{array}{l}\text { Carbon source area } \\
\left(\times 10^{6} \mathrm{ha}\right)\end{array}$ & $\begin{array}{c}\text { Carbon buget } \\
(\mathrm{TgC})\end{array}$ \\
\hline Coniferous forest & 417.40 & 53.97 & 49.80 & 17.04 & 367.60 \\
\hline Broadleaf forest & 445.70 & 48.85 & 62.60 & 12.30 & 383.10 \\
\hline Mixed conifer-broadleaf forest & 16.65 & 4.47 & 2.10 & 3.47 & 14.55 \\
\hline
\end{tabular}

Table 3 Comparison of estimates of China's forest ecosystem carbon sink in the present and previous studies

\begin{tabular}{|c|c|c|c|c|}
\hline Period & $\begin{array}{c}\text { Forest area } \\
\left(10^{6} \mathrm{ha}\right)\end{array}$ & $\begin{array}{l}\text { Total forest vegetation carbon sink } \\
\left(\mathrm{TgC} \mathrm{a}^{-1}\right)\end{array}$ & $\begin{array}{l}\text { Average forest vegetation carbon sink } \\
\qquad\left(\mathrm{gC} \mathrm{m}^{-2} \mathrm{a}^{-1}\right)\end{array}$ & Reference \\
\hline 1984-2003 & 140.05 & 51 & 36.4 & this study \\
\hline 1990-1999 & 142.8 & 60 & 42.0 & [2] \\
\hline $1981-2000$ & 142.8 & 75 & 52.5 & [29] \\
\hline 2000-2007 & 155.6 & 115 & 73.9 & {$[2]$} \\
\hline 1981-2000 & $126-137$ & 82 & 61.3 & [7] \\
\hline 1982-1999 & 124.3 & 34 & 27.4 & {$[32]$} \\
\hline 1981-1999 & 127.9 & 19 & 15.0 & [33] \\
\hline $1990 \mathrm{~s}$ & 130.5 & 66 & 51.6 & [34] \\
\hline
\end{tabular}


forest surveys stated that the canopy density of the forest was 30\%, and subsequently it was defined as $20 \%$ [29], which caused the value of carbon storage computed on the basis of $20 \%$ canopy density to be lower than the real value. Therefore, this study adopted an transfer function for carbon storage in various canopy densities, to correct the carbon storage value for the period from 1984 to 1988 on the basis of $20 \%$ canopy density. This correction resulted in an increase in total biomass from 1984 to 1988 and a relative decrease in carbon sinks from 1984 to 2003.

\subsection{Relationship between carbon sinks and NPP growth}

The carbon sinks of ecosystems originates from the budget imbalance of the carbon cycle, carbon sinks quantity and trend are simultaneously controlled by the internal carbon cycle mechanism of ecosystems and other external driving factors [35]. Therefore, there are two key factors that determined the carbon storage of the forest ecosystems. First, the intensity and long-term trend of NPP growth leads to higher quantities of carbon in the atmosphere to be incorporated into the carbon stocks in forest ecosystems, which makes net carbon absorption possible for an ecosystem. Second, the carbon turnover rate of the forest ecosystem influences the residence time of carbon in the system and ultimately controls the potential of the carbon stock [36,37]. Analysis of the relationship between the spatial distribution of carbon sinks and NPP growth can not only help to improve our understanding of the mechanism underlying the spatial distribution of carbon sinks, but also assist with prediction of the potential of carbon sinks.

In the Chinese forest ecosystem, an obvious relationship between the spatial distribution of intensity of carbon sinks and NPP growth was apparent. During the past 20 years (1984-2003), the intensity of carbon sinks has been deeply influenced by NPP growth (Figure 3). The regression model showed that in four areas (Northeast, North, Northwest and South) the intensity of carbon sinks was apparently influenced by the NPP growth rate to the largest extent. More than $80 \%$ of the change in carbon sinks could be attributed to the influence of NPP growth. Among the four areas, Northeast China showed the strongest influence, and the determinative coefficient of the regression model $\left(R^{2}\right)$ was more than 0.92. In comparison, carbon sinks in Southwest China were not strongly influenced by NPP growth $\left(R^{2}=\right.$ 0.223 ), so there was much more uncertainty in the simulated carbon sinks. This might be related to the variation in the local carbon turnover rate [38] and the spatial hydrothermal change in the local ecosystem, which decreases the possibility for using NPP growth to explain the carbon sinks.

\subsection{Relationship between carbon sinks and forest age}

In the prediction and simulation of carbon storage and carbon sinks in forest ecosystems, forest age is an important parameter $[39,40]$. Forest age and NPP are closely related, which directly influences the quantity and trend of NPP [41]. In addition, forest age affects the distribution of organic compounds and biomass accumulation [42]. Thus forest age is a key parameter for simulation and prediction of the potential of carbon sinks in forest vegetation $[8,43]$.

From 1984 to 2003 there was a strong relationship between the spatial distribution of carbon sinks and that of forest ages in the Chinese forest vegetation. With an average age of about 40 years [44], forest ages in China are generally on the low side, which means these forests possess much higher biomass accumulation and carbon sink intensity.
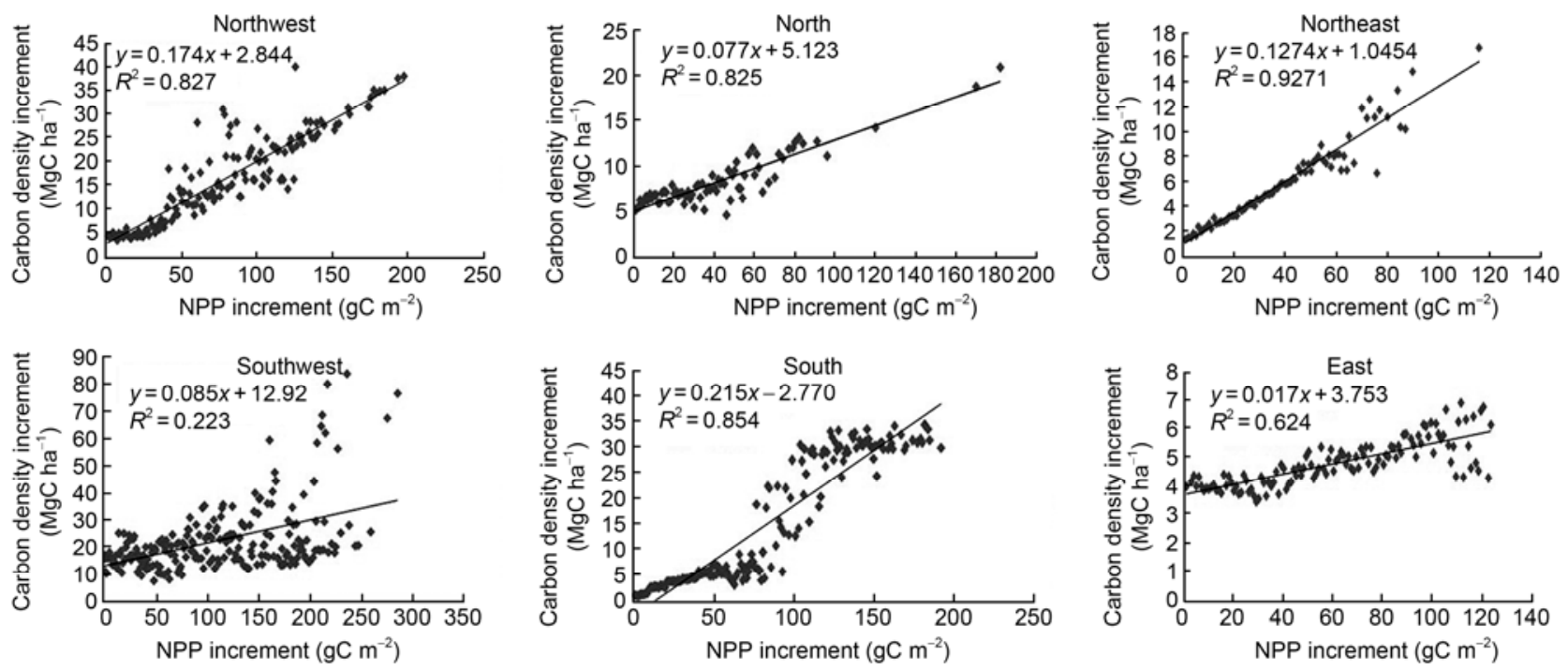

Figure 3 Relationship between the increased net primary productivity of China's major regional forest vegetation and the forest vegetation carbon density increment (not including Taiwan). 
This situation is apparently different from that of North America where the forest ages are much higher [41]. Southeast China has a relatively higher density of carbon sinks (Figure 2), which agrees well with the rather low forest ages (20 to 30 years) in this area [44]; in contrast, in the Southwest area, such as central Sichuan and southern Yunnan, the intensity of carbon sinks is weak and represents carbon sources (Figure 2), which is consistent with the higher forest ages in the western areas of China. The forests with ages exceeding 120 years are mainly found in the central Sichuan Province [44].

Apart from forest age, other factors such as human activities and hydrothermal conditions might jointly influence the carbon sinks of forest vegetation. To explore the relationship between the distribution of carbon sinks and the age of Chinese forests, we chose the Northwest area where human activities are relatively rare and hydrothermal conditions are stable as an example, and quantitatively analyzed the relationship (Figure 4). During the study period (19842003), among the different age groups, the variation in carbon density of half-mature forest and large sapling forest was maximal and their carbon-sink intensity was highest; in contrast, variation in carbon density of near-mature forest and mature forest was relatively minor and that of overmature forest was the lowest (Figure 4). Figure 4 reflected relationship between the variation in carbon density and forest age, What are the same relationship by Logistic Model [43].

The results of the sixth inventory of national forest resources in China showed that, compared with natural forests, Plantation forests are younger but are high in potential as carbon sinks. In natural forests, the area of half-mature forest was largest $(34.07 \%)$, followed by large sapling forest $(30.99 \%)$. In man-made forests, the area of large sapling forests was highest $(40.24 \%)$, followed by half-mature forest $(37.16 \%)$. The imbalance in the distribution of manmade forests in China influenced the distribution of carbon sinks among the forest vegetation. For example, the six administrative regions (Inner Mongolia, Sichuan, Fujian, Hunan, Guangdong and Guangxi) that have a relatively large

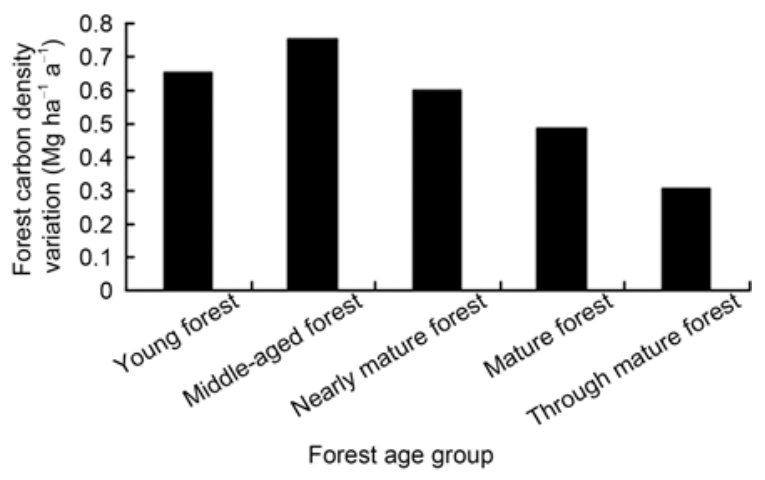

Figure 4 Relationship between forest age classes and the variation in forest carbon density. area of man-made forests all have a higher net budget of carbon sinks, of which Inner Mongolia, Sichuan, Fujian and Hunan were especially outstanding. However, since the percentage of the area and the growing stock volume in the forests is not that high $(21.0 \%$ and $11.45 \%$, respectively), a simple corresponding relationship between the distribution of carbon sinks and man-made forests was not observed.

\subsection{Uncertainty of carbon sink results}

The spatial distribution of carbon sources and carbon sinks of forest vegetation can be influenced by many complicated factors such as natural factors or perturbation (such as the fertilization effect caused by the rising density of $\mathrm{CO}_{2}$ in the atmosphere, nitrogen deposition, climate change, fire, plant diseases and insect pests) and human activities (such as trees felling and planting). Therefore, we still face many uncertainties before we can systematically distinguish the carbon sinks caused by natural factors from those caused by human factors. From the mechanism that the forest carbon sink is rooted in forest restoration and forest enhancement. These two modes can equally lead to change in forest age as well of the NPP of forest ecosystems that are monitored by remote sensing. This is reflected in the downscaling estimation, but more intensive research is required to accurately distinguish the contribution of the above factors.

The present research utilized a two-period spatial distribution map of carbon density in Chinese forest vegetation and adopted the same forest type map $(1: 1000000)$, which did not reflect the effects of land use change. We are currently digitizing the Atlas of Chinese Forest Resources [45] to establish whether determination of the spatial distribution of carbon sources and carbon sinks from the two different forest type maps corresponds well with data from forest inventories of different time periods. However, in the Atlas of Chinese Forest Resources, the area of forest cover is $115.59 \times 10^{6}$ ha, and that of the forest vegetation map $(1: 1000000)$ is $151.44 \times 10^{6}$ ha (Taiwan is included); both differ somewhat from the area $\left((120.99-142.79) \times 10^{6}\right.$ ha) covered in the forest survey. The forest vegetation map $(1: 1000000)$ is presently considered to be the best reference map, and the revision of this version took a long time and reflected the forest types in the 1980s and 1990s, which coincidentally matched the study period of our research. In addition, large-scale forestry construction projects were launched in 2002, which affect the natural growth of forest carbon sink/source was relatively small in this period.

In the present research, the estimations of NPP of the forest ecosystem simulated by the CASA model from light use efficiency depend on data for NDVI. For long-term dynamic monitoring of vegetation, data for NDVI are usually obtained from, for example, GIMMS NDIV, MODIS NDVI, and SPOT-Vegetation NDVI data sets. Some differences exist in the transducer and calculations used to compile these data sets, therefore the NPP and biomass estimations obtained 
from different NDVI data sets might be slightly different, which can lead to uncertainty in the estimation of carbon sinks. In the present study, we used the GIMMS NDVI data set to simulate NPP, because in comparison with other NDVI products (such as MODIS NDVI and SPOT- Vegetation NDVI), GIMMS NDVI has a longer temporal series (1981-2006) that completely covered the study period (1984-2003) in our research. This helped us to avoid potential inaccuracy caused by estimations derived from different transducers and data sets.

Comparison of the present results with those of other methods based on remote sensing or forest surveys (Table 3) indicated that the downscaling estimation of carbon sinks derived from combination of remote sensing and survey data in one respect retained the spatial advantages of remote sensing data, and also retained the advantages of the accuracy of forest surveys. Thus estimations of carbon sources and carbon sinks approached the results of the surveys, and thus effectively reducing the remote sensing data and the model itself in the systematic calibration error.

\section{Conclusions}

From 1984 to 2003, the Chinese forest vegetation represented a carbon sink for atmospheric $\mathrm{CO}_{2}$, the increment in carbon storage was $0.77 \mathrm{PgC}$, and the average annual increment was about $51.0 \mathrm{Tg} \mathrm{Ca}^{-1}$. Among total carbon storage changes, the amount of carbon fixed was $0.88 \mathrm{PgC}$, and the amount of carbon released was $0.11 \mathrm{PgC}$. Some patterns in the distribution of carbon sinks in the Chinese forest vegetation were apparent. Carbon sinks were concentrated in subtropical and temperate areas, whereas sources were mainly distributed from Northeast to Southwest China. The densities of carbon sinks were strongly related with the increment of NPP and the spatial distribution of forest age. Carbon sink intensity decreased with increase in forest age. The downscaling technique can effectively combine the spatial features of the remote sensing data with the statistical features of ground surveys. Thus, the method retains the advantages of the spatial distribution of remote sense data and the advantages of accuracy of forest surveys. Therefore, the carbon sources and carbon sinks were not only accurate in quantity, but also in the spatial distribution of grids.

We thank two anonymous referees for their constructive and corrective advice. This work was supported by the National Basic Research Program of China (2012CB955401), the National Natural Science Foundation of China (30970514 and 30590384) and the New Century Excellent Talents in University (NCET-10-0251).

1 Raupach M R. Carbon cycle: Pinning down the land carbon sink. Nat Clim Change, 2011, 1: 148-149

2 Pan Y D, Birdsey R A, Fang J Y, et al. A large and persistent carbon sink in the world's forests. Science, 2011, 333: 988-993
3 Xu F D, Wang R H, Li Y X, et al. Review on carbon cycle in terrestrial ecosystem and its influenced factors (in Chinese). Chin J Agrometeorol, 2009, 30: 519-524

4 Yu G Y, Wang Q F, Zhu X J. Methods and uncertainties in evaluating the carbon budgets of regional terrestrial ecosystems (in Chinese). Prog Geogr, 2011, 30: 103-113

5 Xu X L, Cao M K, Li K R. Temporal-spatial dynamics of carbon storage of forest vegetation in China (in Chinese). Prog Geogr, 2007, 26: $1-10$

6 Wang X K, Feng Z W, Ouyang Z Y. Vegetation carbon storage and density of forest ecosystems in China (in Chinese). Chin J Appl Ecol, 2001, 12: 13-16

7 Tian H, Melillo J, Lu C, et al. China's terrestrial carbon balance: Contribution from multiple global change factors. Glob Biogeochem Cycle, 2011, 25: GB1007

8 Wang S Q, Zhou L, Chen J M, et al. Relationships between net primary productivity and stand age for several forest types and their influence on China's carbon balance. J Environ Manage, 2011, 92: 1651-1662

9 Ma X Z, Wang Z. Estimation of provincial forest carbon sink capacities in Chinese mainland. Chin Sci Bull, 2011, 56: 433-439

10 Zhao M, Zhou G S. Carbon storage of forest vegetation and its relationship with climatic factors (in Chinese). Sci Geogr Sin, 2004, 24: 50-54

11 Zhou R Y, Yu Z L, Zhao S D. carbon storage and budget of major Chinese forest types (in Chinese). Atca Phytoecol Sin, 2000, 24: 518-522

12 Piao S L, Fang J Y, Ciais P, et al. The carbon balance of terrestrial ecosystems in China. Nature, 2009, 458: 1009-1013

13 Tomppo E, Nilsson M, Rosengren M, et al. Simultaneous use of Landsat-TM and IRS-1C WiFS data in estimating large area tree stem volume and aboveground biomass. Remote Sens Environ, 2002, 82: 156-171

14 Zheng D, Heath L S, Ducey M J. Forest biomass estimated from MODIS and FIA data in the Lake States: MN, WI and MI, USA. Forestry, 2007, 80: 265-278

15 Blackard J A, Finco M V, Helmer E H, et al. Mapping U.S. forest biomass using nationwide forest inventory data and moderate resolution information. Remote Sens Environ, 2008, 112: 1658-1677

16 Kindermann G E, McCallum I, Fritz S, et al. A global forest growing stock, biomass and carbon map based on FAO statistics. Silva Fennica, 2008, 42: 387-396

17 Paivinen R, Brusselen J V, Schuck A. The growing stock of European forests using remote sensing and forest inventory data. Forestry, 2009, 82: 479-490

18 Tucker C J, Pinzon J E, Brown M E. Global Inventory Modeling and Mapping Studies, NA94apr15b.n11-VIg, 2.0, 2004, Global Land Cover Facility, University of Maryland, College Park, Maryland, 04/15/1994

19 Pinzon J, Brown M E, Tucker C J. Satellite time series correction of orbital drift artifacts using empirical mode decomposition. In: Huang N, ed. Hilbert-Huang Transform: Introduction and Applications, 2005. 167-186

20 Tucker C J, Pinzon J E, Brown M E, et al. An Extended AVHRR 8-km NDVI Data Set Compatible with MODIS and SPOT Vegetation NDVI Data. Int J Remote Sens, 2005, 26: 4485-5598

21 Potter C S, Randerson J T, Field C B, et al. Terrestrial ecosystem production: A process model based on global satellite and surface data. Glob Biogeochem Cycle, 1993, 7: 811-841

22 Piao S L, Fang J Y, Zhou L M, et al. Changes in vegetation net primary productivity from 1982 to 1999 in China. Global Biogeochem Cycle, 2005, 19: GB2027

23 Zhu W Q, Pan Y Z, He H, et al. Simulation of maximum light use efficiency for some typical vegetation types in China (in Chinese). Chin Sci Bull, 2006, 51: 457-463

24 Hicke J A, Asner G P, Randerson J T, et al. Trends in North American net primary productivity derived from satellite observations, 1982-1998. Glob Biogeochem Cycle, 2002, 16: 1018

25 Lobell D B, Hicke J A, Asner G P, et al. Satellite estimates of 
productivity and light use efficiency in United States agriculture, 1982-1998. Glob Change Biol, 2002, 8: 722-735

26 Lovett R A. Rain might be leading carbon sink factor. Science, 2002, 296: 1787

27 Fang J Y, Liu G H, Xu S L. Biomass and net production of forest vegetation in China (in Chinese). Acta Ecol Sin, 1996, 16: 497-508

28 Fang J Y, Chen A P, Peng C H, et al. Changes in forest biomass carbon storage in China between 1949 and 1998. Science, 2001, 292: 2320-2322

29 Fang J Y, Guo Z D, Piao S L, et al. Terrestrial vegetation carbon sinks in China, 1981-2000. Sci China Ser D-Earth Sci, 2007, 50: 1341-1350

30 Field C B, Randerson J T, Malmstrom C M. Global net primary production: Combining ecology and remote sensing. Remote Sens Environ, 1995, 51: 74-88

31 Zhu W Q, Pan Y Z, Yang X Q, et al. Comprehensive analysis of the impact of climatic changes on Chinese terrestrial net primary productivity. Chin Sci Bull, 2007, 52: 3253-3260

32 Li X J, Zhou T, He X Z. Carbon sink of forest ecosystem driven by NPP increasing in China (in Chinese). J Nat Resour, 2009, 24: 491-497

33 Piao S L, Fang J Y, Zhu B, et al. Forest biomass carbon stocks in China over the past 2 decades: Estimation based on integrated inventory and satellite data. J Geophys Res, 2005, 110: G01006

34 Pan Y D, Luo T X, Birdsey R, et al. New estimations of carbon storage and sequestration in China's forests: Effects of age-class and method on inventory-based carbon estimation. Clim Change, 2004, 67: $211-236$

35 Luo Y Q, Weng E S. Dynamic disequilibrium of the terrestrial carbon cycle under global change. Trends Ecol Evol, 2011, 26: 96-104
36 Luo Y Q, White L W, Canadell J G, et al. Sustainability of terrestrial carbon sequestration: A case study in Duke Forest with inversion approach. Glob Biogeochem Cycles, 2003, 17: 1021

37 Zhou T, Luo Y Q. Spatial patterns of ecosystem carbon residence time and NPP-driven carbon uptake in the conterminous United States. Glob Biogeochem Cycle, 2008, 22: GB3032

38 Zhou T, Shi P J, Jia G S, et al. Spatial patterns of ecosystem carbon residence time in Chinese forests. Sci China Ser D-Earth Sci, 2010, 53: $1229-1240$

39 Chen J M, Ju W, Cihlar J, et al. Spatial distribution of carbon sources and sinks in Canada's forests. Tellus B, 2003, 55: 622-641

40 Bradford J B, Birdsey R A, Joyce L A, et al. Tree age, disturbance history, and carbon stocks and fluxes in subalpine Rocky Mountain forests. Glob Change Biol, 2008, 14: 2882-2897

41 Chen W, Chen J, Price D T, et al. Effects of stand age on net primary productivity of boreal black spruce forests in Ontario, Canada. Can J Forest Res, 2002, 32: 833-842

42 Piao S L, Luyssaert S, Ciais P, et al. Forest annual carbon cost: A global-scale analysis of autotrophic respiration. Ecology, 2010, 91: $652-661$

43 Xu B, Guo Z D, Piao S L, et al. Biomass carbon stocks in China's forests between 2000 and 2050: A prediction based on forest biomass- age relationships. Sci China Ser D-Earth Sci, 2010, 53: 776-783

44 Dai M, Zhou T, Yang L L, et al. Spatial pattern of forest ages in China retrieved from national-level inventory and remote sensing imageries (in Chinese). Geogr Res, 2011, 30: 172-184

45 Xiao X W. Atlas of Forest Resources in China (in Chinese). Beijing: China Forestry Publishing House, 2005

Open Access This article is distributed under the terms of the Creative Commons Attribution License which permits any use, distribution, and reproduction in any medium, provided the original author(s) and source are credited. 